\title{
sciendo
}

\author{
WERONIKA WASYLUK ${ }^{1}$, GABRIELA ZDUNEK ${ }^{2}$, AGNIESZKA PEDRYCZ ${ }^{3}$
}

\section{The impact of carbohydrate intake on the behavior and cognitive functions of children and adolescents}

\begin{abstract}
Introduction. Although carbohydrates are the most commonly studied nutrients regarding their influence on cognitive functions, there is no unequivocal agreement on whether this influence really exists and what its manifestations are.

Aim. This study is a literature review of research on the association between sugar intake, behavior and cognitive functions in children population.

Material and methods. The analysis of the studies on the carbohydrate intake and its impact on behavior and cognitive functions of children and adolescents on the basis of MEDLINE database was conducted. The studies were found in PubMed Internet search engine. The following words were implemented in various combinations: "sugar", "carbohydrate", "glycemic index", “GI", "glucose” as well as "cognition", "cognitive", "learning”, “memory", "attention”, "behavior", "hyperactivity”. The number of 27 publications was chosen and the information they contained was analyzed.

Results. Despite multiple studies on the impact of carbohydrate intake and their glycemic index on cognitive functions, there is still no agreement on this issue. Multiple studies indicate the association between glycemic index and cognitive processes. The positive impact of low GI breakfast intake on the concentration and memory is relatively frequently emphasized. The concept that indicates the association between sugar intake and hyperactive behavior among children also has not been unequivocally confirmed in the analyzed studies - contrarily - some of them indicated lack of such relationship. The placebo effect may be the explanation for the above concept. The association between the number of carbohydrates in diet and sleep disorders also has not been proved.

Conclusions. Although there are no unequivocal scientific foundations to limit the intake of simple sugars and consume polysaccharides with low GI to improve behavior and cognitive functions, such actions are consistent with a healthy diet and should be recommended for children and adolescents.
\end{abstract}

Keywords: sugar, diet, memory, learning, behavior, glycemic index.

DOI: $10.2478 /$ pjph-2019-0015

\section{INTRODUCTION}

Both parents and teachers claim that carbohydrate has an impact on children's concentration and behavior. There exists a common opinion which states that directly after simple sugar consumption, children are hyperactive and have difficulty focusing. This study aims at the literature review of the studies on the association between carbohydrate intake, behavior, and cognitive functions among children and adolescents. The study is a literature review. The publications were found through PubMed Internet search engine. The following words were implemented in various combinations:: "sugar", "carbohydrate", "glycemic index", "GI", "glucose", as well as "cognition", "cognitive", "learning", "memory", "attention", "behavior", "hyperactivity". After that, the results were selected based on the subject of the publications and the significance of the presented results.

\section{The significance of carbohydrates in a diet}

Carbohydrates are the main source of energy in the human diet. With regards to their structure, carbohydrates can be divided into monosaccharides (simple sugars), disaccharides, oligosaccharides and polysaccharides (Figure 1). Moreover, with regards to metabolism, carbohydrates can be divided into digestive and non-digestive ones (Figure 2). Digestive carbohydrates are digested in the small intestine, after digestion they are absorbed and have an effect on glycemia. On the other hand, non-digestive carbohydrates, such as dietary fiber, are not digested and are the substrate for gut microbiota [1].

The term "sugars" or "simple carbohydrates" in dietary terminology means mono- and disaccharides (e.g. glucose, fructose, galactose, saccharose). Moreover, in dietary terminology there exists the term "free sugars" which is defined as monoand disaccharides added to food and drinks or naturally occurring in fruit juices and honey.

\footnotetext{
${ }^{1}$ Graduate, Medical University in Lublin, Poland

${ }^{2}$ Medical University of Warsaw, Poland

${ }^{3}$ Chair and Department of Histology and Embryology with Experimental Cytology Unit, Medical University in Lublin, Poland
} 


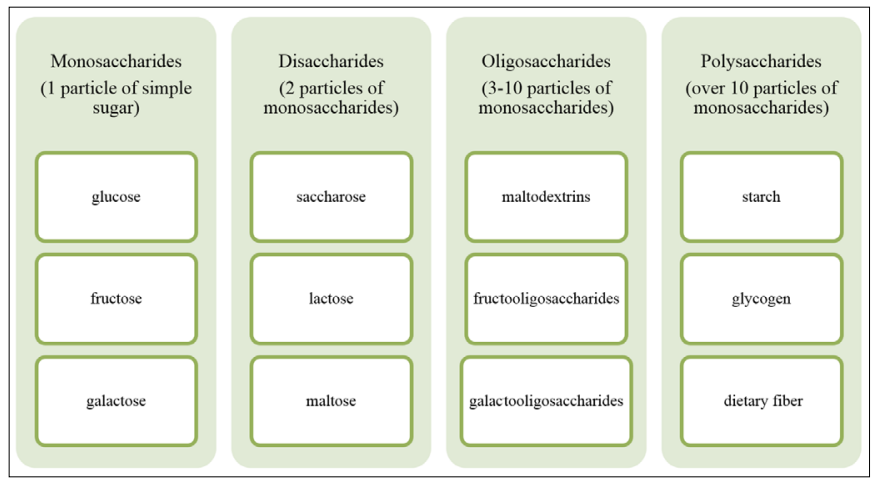

FIGURE 1. The division of carbohydrates according to particle structure with examples.

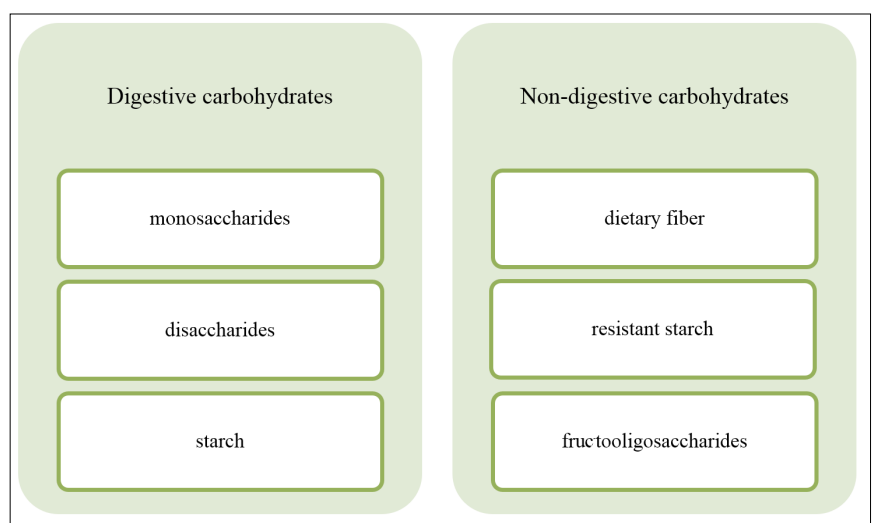

FIGURE 2. The division of carbohydrates according to metabolism with examples.

As mentioned before, carbohydrates are the main source of energy in human body. Usually, they deliver around $50-60 \%$ of essential calories. Moreover, they are the main and, in physiological conditions, the only source of energy for the central nervous system (CNS). Therefore, the most important factor that determines the demand for carbohydrates is the energetic needs of CNS. It has been estimated that independently of age, the demand for carbohydrates is around $100 \mathrm{~g}$ per day and based on further calculations, the recommended amount of carbohydrate intake is around $130 \mathrm{~g}$ per day (those recommendations do not include pregnant and breastfeeding women and infants) [2].

Current recommended intake of carbohydrates for the Polish population (for all age groups except for infants) constitutes $45-65 \%$ of all the energy from foods. However, simple sugars should not exceed $10 \%$ of all the energetic supply and should be delivered mainly from natural sources $[1,2]$.

\section{The influence of sugar on cognitive functions and intelli- gence}

The fact that food may influence cognitive functions is commonly known and proved in scientific studies [3-5]. Due to the obvious association with CNS metabolism, many studies have analyzed the impact of simple sugar intake on cognitive functions [6-9].

In the studies conducted in the last decade of the $20^{\text {th }}$ century and at the beginning of the first decade of the $21^{\text {st }}$ century, this correlation was assessed based on placebo-controlled trials in which the participants ingested glucose solution and then participated in tests that assessed their cognitive functions. Although the results of the studies are not consistent, most of them indicate the positive impact of glucose on cognitive functions. The tests proved memory, especially long-term memory, to be the cognitive process most susceptible to the positive influence of carbohydrates. However, only based on the tests, it is difficult to say whether the memory improvement is due to glucose, foods rich in carbohydrates or whether the memory is susceptible to all the manipulations with macroelements [10]. In the following studies, the influence of other carbohydrates was also assessed, taking into consideration factors such as glycemic index (GI), glycemic load (GL) and other features characterizing the time of carbohydrate absorption. The kind of carbohydrate, the source, and the dosage have an impact on the rise time of glycemia.

Due to different CNS susceptibility to glucose in children compared to adults (higher susceptibility to glycemia fluctuations, greater brain mass compared to body mass and higher brain activity per mass unit [11]), in the further part of this study, the results for the first population will mainly be analyzed.

In the study with the participation of children aged 6-11, the influence of breakfast GI on concentration and memory was assessed. The assessment was made with the help of computer tests - they were performed every hour for 3 hours after breakfast. It has been proved that the efficiency of concentration and memory decreases with time after meal consumption and breakfast with low GI slightly prolongs this time [12]. In a different study, in which the participants were also schoolage children, the concentration and memory were compared after the intake of glucose or cereals on empty stomach. In a group that consumed glucose, the decrease was quicker than in a group that had cereals containing polysaccharides [13]. Another study was performed among children aged 6-7, who received breakfasts with similar energetic value, however with different GI. Approximately 2-3 hours after breakfast, the group that received a meal with lower GI had better results in memory and concentration tests and was less susceptible to frustration [14].

The influence of breakfast's GI on cognitive functions was also assessed in a randomized control study in a group of children aged 11-14. Apart from cognitive functions mood, blood glucose level and cortisol levels in saliva were also assessed. In a group that received a meal with a lower GI, the children proved to be more alert, less nervous and were in a better mood. The conclusion was that low GI and high GL breakfast may have a positive influence on learning [15]. In a different study performed by the same researchers, there was an improvement of short-term memory (assessed with immediate word recall test), operative memory and concentration (assessed with serial seven test) after low GI breakfast. The influence of GL on cognitive functions was also assessed. It was proved that high GL breakfast also benefits operative memory and concentration as well as improves the efficacy of inductive reasoning [16]. The results led researchers to the conclusion that the influence of the GI of a meal on cognitive functions may be domain specific [15]. An observation from the study was also that breakfasts with high GL and low GI were associated with better results in tests that the participants reported as the most difficult. It is coherent with the previous studies [17-20], which suggested that the influence of glucose on cognitive functions depends on the difficulty of the tasks (for the influence to be noticed, the tasks should be adequately demanding) [16].

Smith and Foster, though, proved the benefits of having high GI breakfast. A group that received cereals with high GI had better results in recalling words memorized earlier 
in distracting conditions. The authors associate this phenomenon with faster glucose delivery to bloodstream and optimal brain energy supply during the time of memorizing [21].

In Teheran, Iran, there was relatively vast research conducted which assessed the influence of processed carbohydrates intake on non-verbal intelligence among 245 primary school students aged 6-7. A reverse correlation was proved in participants between processed carbohydrates and non-verbal intelligence [22].

Until now, the obtained results have indicated the need for further studies on the influence of the intake of carbohydrates on particular components of cognitive functions. Moreover, the limitation of most available studies are relatively small study groups (usually several dozens of participants).

\section{The influence of sugar on behavior}

There exists a popular theory that sugar has an influence on children's behavior and increases psychomotor activity. However, already in 1995, there was a metanalysis of 16 studies, which proved that sugar does not influence children's behavior, with a reservation that a slight influence on particular groups of children cannot be discarded [23]. From that time, there were next studies published with inconsistent results. Iran study from 2012 showed a correlation between a high level of added sugar in the diet and the prevalence of attention-deficit hyperactivity disorder (ADHD) [24]. In the same year, the results of a major study with the participation of Korean children was published. The study demonstrated that a high intake of simple sugars, salt, and fried foods is associated with difficulties in studying and behavior. On the other hand, a balanced diet, regular meal intake, and diet rich in dairy products and vegetables are associated with less difficulty in studying and behavior [25]. Another study assessed the relationship between fast food product intake, mean intake of non-milk extrinsic sugar (NMES) and development of behavioral problems in the subsequent 16 months in children aged 81 months. Despite the abundant group, the relationship between these factors was not proved [26]. The relationship between the level of sugar intake and the prevalence of ADHD was not proved as well [27-29].

In 2018 there was a study with the participation of children aged 8-12 performed which proved that a high level of sugar intake does not affect behavior issues and sleeping problems.

The correlation between the level of added sugar and sodium intake and the prevalence of externalizing behaviors among pre-school children was also assessed. It was proved that such a correlation exists, however, it differs depending on sex. Girls who presented behavior disorders had higher sodium levels per $1000 \mathrm{kcal}$ and lower energy from added sugars than girls without such disorders. On the other hand, boys who presented externalizing behaviors had a higher dietary intake of added sugars and less sodium than others [30].

Interesting results were published in the 1994 Journal of Abnormal Child Psychology. There was a study in which the mothers of boys aged 5-7, who described their children as "susceptible to sugar" were randomly divided into two groups. In a study group, the mothers were informed that their sons received a high dose of sugar while in the control group - the placebo. In reality in both groups children received a placebo. The mothers who thought their children had received sugar described the children as much more active. Also, their attitude towards the children differed from the control group [31].

\section{CONCLUSIONS}

Despite multiple studies on the carbohydrate intake and their GI on cognitive functions, the consensus on this issue has still not been reached. Although the results are not coherent, many studies prove a relationship between GI and cognitive processes. The positive impact of a breakfast containing carbohydrates with low GI on concentration and memory is often emphasized.

Also, the theory that indicates the relationship between high intake of sugars and hyperactive behaviors has not been confirmed in scientific research, contrarily - some of them proved no such correlation. The popularity of this theory may be explained by the placebo effect. The relationship between carbohydrates intake and sleeping problems has neither been proved.

Although there are no unequivocal scientific foundations to limit the intake of simple sugars and to eat polysaccharides instead to improve behavior and cognitive functions, it is coherent with healthy diet recommendations and should be recommended for the population of children and adolescents. Good nutrition of children is the basis of sustainable development and, according to Maslow's hierarchy of needs, it is the condition needed to reach success in the tasks from higher levels, among which there is pedagogical and therapeutic behavior.

\section{REFERENCES}

1. Horvath A, Rachtan-Janicka J. Podstawowe zapotrzebowanie energetyczne. In: H. Szajewska. Żywienie i leczenie żywieniowe dzieci i młodzieży. Kraków: Medycyna Praktyczna; 2017. p. 22-31.

2. Jarosz M, Sajór I, Gugała-Mirosz S, et al. In: M. Jarosz. Normy żywienia dla populacji Polski. Warszawa: Instytut Żywności i Żywienia; 2017. p. $98-114$

3. Dye L, Blundell J. Functional foods: psychological and behavioural functions. Br J Nutr. 2002;88(Suppl 2):187-211.

4. Schmitt JA, Benton D, Kallus KW. General methodological considerations for the assessment of nutritional influences on human cognitive functions. Eur J Nutr. 2005;44(8):459-64.

5. Westenhoefer J, Bellisle F, Blundell JE, et al. PASSCLAIM -mental state and performance. Eur J Nutr. 2004;43(Suppl 2):II85-II117.

6. Riby LM. The impact of age and task domain on cognitive performance: a meta-analytical review of the glucose facilitation effect. Brain Impairment. 2004;5:145-65.

7. Leigh Gibson E, Green MW. Nutritional influences on cognitive function mechanisms of susceptibility. Nutr Res Rev. 2002;15(1):169-206.

8. Messier C. Glucose improvement of memory: a review. Eur J Pharmacol. 2004;490(1-3):33-57.

9. Gilsenan MB, de Bruin EA, Dye L. The influence of carbohydrate on cognitive performance: a critical evaluation from the perspective of glycaemic load. Br J Nutr. 2009;107(1):941-9.

10. Hoyland A, Lawton CL, Dye L. Acute effects of macronutrient manipulations on cognitive test performance in healthy young adults: A systematic research review. Neurosci Biobehav R. 2008;32(1):72-85.

11. Chugani HT. A critical period of brain development: studies of cerebral glucose utilization with PET. Prev Med. 1998;27(2):184-8.

12. Ingwersen J, Defeyter MA, Kennedy DO, et al. A low glycaemic index breakfast cereal preferentially prevents children's cognitive performance from declining throughout the morning. Appetite. 2007;49(1):240-4.

13. Wesnes KA, Pincock C, Richardson D, et al. Breakfast reduces declines in attention and memory over the morning in schoolchildren. Appetite. 2003;41(3):329-31.

14. Benton D, Maconie A, Williams C. The influence of the glycaemic load of breakfast on the behaviour of children in school. Physiol Behav. 2007;92(4):717-24. 
15. Micha R, Rogers PJ, Nelson M. Glycaemic index and glycaemic load of breakfast predict cognitive function and mood in school children: a randomised controlled trial. Br J Nutr. 2011;106(10):1552-61.

16. Micha R, Rogers PJ, Nelson M. The glycaemic potency of breakfast and cognitive function in school children. Eur J Clin Nutr. 2010;64(9):948-57.

17. Donohoe RT, Benton D. Cognitive functioning is susceptible to the level of blood glucose. Psychopharmacology (Berl). 1999;145:378-85.

18. Owens DS, Parker PY, Benton D. Blood glucose and subjective energy following cognitive demand. Physiol Behav. 1997;62:471-8.

19. Scholey AB, Harper S, Kennedy DO. Cognitive demand and blood glucose. Physiol Behav. 2001;73:585-92.

20. Sunram-Lea SI, Foster JK, Durlach P, Perez C. Glucose facilitation of cognitive performance in healthy young adults: examination of the influence of fast-duration, time of day and pre-consumption plasma glucose levels. Psychopharmacology (Berl). 2001;157:46-54.

21. Smith MA, Foster JK. The impact of a high versus a low glycaemic index breakfast cereal meal on verbal episodic memory in healthy adolescents. Nutr Neurosci. 2008;11(5):219-27.

22. Abargouei AS, Kalantari N, Omidvar N, et al. Refined carbohydrate intake in relation to non-verbal intelligence among Tehrani schoolchildren. Public Health Nutr. 2012;15(10):1925-31.

23. Wolraich ML, Wilson DB, White JW. The effect of sugar on behavior or cognition in children. A meta-analysis. 1995;274(20):1617-21.

24. Azadbakht L, Esmaillzadeh A. Dietary patterns and attention deficit hyperactivity disorder among Iranian children. Nutrition. 2012;28(3):242-9.

25. Park S, Cho SC, Hong YC, et al. Association between dietary behaviors and attention-deficit/hyperactivity disorder and learning disabilities in school-aged children. Psychiatry Res. 2012;198(3):468-76.

26. Peacock PJ, Lewis G, Northstone K, Wiles NJ. Childhood diet and behavioural problems: results from the ALSPAC cohort. Eur J Clin Nutr. 2011;65(6):720-6.

27. Kim Y, Chang H. Correlation between attention deficit hyperactivity disorder and sugar consumption, quality of diet, and dietary behavior in school children. Nutr Res Pract. 2011;5(3):236-45.

28. Del-Ponte B, Anselmi L, Assunção MCF, et al. Sugar consumption and attention-deficit/hyperactivity disorder (ADHD): A birth cohort study. J Affect Disord. 2019;243:290-6.

29. Watson EJ, Coates AM, Banks S, Kohler M. Total dietary sugar consumption does not influence sleep or behaviour in Australian children. Int $\mathrm{J}$ Food Sci Nutr. 2018;64(3):503-12.

30. Jansen EC, Miller AL, Lumeng JC, et al. Externalizing behavior is prospectively associated with intake of added sugar and sodium among low socioeconomic status preschoolers in a sex-specific manner. Int J Behav Nutr Phys Act. 2017;3:135.

31. Hoover DW, Milich R. Effects of sugar ingestion expectancies on motherchild interactions. J Abnorm Child Psychol. 1994;22(4):501-15.
Corresponding author

Weronika Wasyluk

Medical University of Lublin

E-mail:weronika.wasyluk@gmail.com 